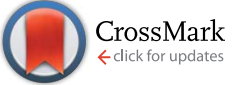

Cite this: RSC Adv., 2017, 7, 1432
Received 6th October 2016 Accepted 29th November 2016

DOI: 10.1039/c6ra24793h

www.rsc.org/advances

\section{Fluorescence sensor for detecting protamines based on competitive interactions of polyacrylic acid modified with sodium 4-amino-1- naphthalenesulfonate with protamines and aminated graphene oxide $\uparrow$}

\begin{abstract}
Jinshui Liu, Meijiao Xu, Bin Wang, Zihan Zhou and Lizhen Wang
An easy-to-use fluorescent probe for detecting protamines was developed. Protamines are detected using the probe because of competitive interactions of polyacrylic acid modified with sodium 4-amino-1naphthalenesulfonate (ANS-PAA) with protamines and aminated graphene oxide $\left(\mathrm{GO}-\mathrm{NH}_{2}\right)$. The ANSPAA fluorescence was effectively quenched by the $\mathrm{GO}-\mathrm{NH}_{2}$, the high quenching efficiency being caused by the ANS-PAA becoming non-covalently bound to the $\mathrm{GO}-\mathrm{NH}_{2}$ surface through electrostatic interactions, forming a ANS-PAA/GO- $\mathrm{NH}_{2}$ complex. Adding protamines recovered the fluorescence of the ANS-PAA/GO-NH $\mathrm{N}_{2}$ complex. This recovery was due to the positively charged protamines removing ANS-PAA from the GO- $\mathrm{NH}_{2}$ surfaces and forming ANS-PAA/protamine complexes. Displacement of GO$\mathrm{NH}_{2}$ by protamines gave a high fluorescence recovery efficiency. Under optimal conditions, the fluorescence intensity when protamines were added was proportional to the protamine concentration over the range 0 to $6.0 \mu \mathrm{g} \mathrm{mL}^{-1}$. The detection limit was $0.4 \mu \mathrm{g} \mathrm{mL} \mathrm{L}^{-1}$. This approach offers a new quantitative method for determining protamines.
\end{abstract}

\section{Introduction}

Protamines are strongly cationic peptides with molecular masses of approximately $6000 \mathrm{Da}$ that are found in the spermatic cells of vertebrates and cephalopods. ${ }^{1}$ The primary polypeptide sequence of a protamine can have an arginine content of up to $67 \%$, so protamines are highly positively charged. ${ }^{2}$ Protamines have been separated from the sperm of salmon and other fish species. Protamines are now able to be produced using recombinant biotechnology. Protamines are important pharmaceuticals that are used in cardiac surgery, vascular surgery, and interventional radiology procedures as an antidote for heparin (used to treat and prevent blood clots) overdose. ${ }^{3}$ Protamines can also prolong insulin release in diabetes mellitus therapies. However, overusing protamines can lead to adverse effects such as hypotension and idiosyncratic fatal cardiac arrest. ${ }^{4}$ Detecting and quantifying protamines is therefore crucial to clinical procedures. A number of approaches have been developed for detecting protamines, including

College of Chemistry and Materials Science, The Key Laboratory of Functional Molecular Solids, Ministry of Education, Anhui Key Laboratory of Chemo/Biosensing, Anhui Laboratory of Molecule-Based Materials, Anhui Normal University, Wuhu 241000, PR China.E-mail: jsliu@sina.com

$\dagger$ Electronic supplementary information (ESI) available. See DOI: 10.1039/c6ra24793h electrochemical methods, ${ }^{5}$ chromatographic methods, ${ }^{6}$ and colorimetric methods. ${ }^{7,8}$ These methods offer reasonable sensitivities and specificities, but some are inaccurate, complicated, time-consuming, or have poor reproducibilities. It is therefore highly desirable to develop a simple, rapid, and sensitive method for detecting protamines. Fluorescence methods are the most promising alternative methods for detecting protamines because they offer advantages over other techniques, including their speed, ease of use, and sensitivities. $^{9-13}$ A large number of fluorescence probes have been developed for sensitively detecting protamine, but, to the best of our knowledge, only a few methods have been developed in which protamine is detected using fluorescence turn-on sensors. ${ }^{11,12}$ Fluorescence turn-on sensors offer advantages over fluorescence quenching sensors in that there is less chance of false positive signals being obtained and sensitivities and selectivities are better using fluorescence turn-on sensors than using fluorescence quenching sensors, as has been demonstrated in numerous studies. ${ }^{\mathbf{1 4}}$ The development of an environmentally friendly turn-on probe for detecting protamine is still a challenge.

Graphene oxide (GO), which is a two-dimensional nanosheet, has effective electron transfer properties that allow it to strongly quench fluorescence, and these properties have been used creatively in GO-quenched optical sensors for various analytes. ${ }^{15-17}$ However, to the best of our knowledge, all GO- 
complex fluorescence sensors that have previously been developed have used pristine GO, the surfaces of which always have negative charges (on the intrinsic carboxyl groups). These negative charges keep GO well dispersed in aqueous solutions but weaken interactions between anionic dyes and GO because of electrostatic repulsion, meaning the quenching efficiencies of the anionic dyes will not be as high as might be desirable. GO modified with amine groups $\left(\mathrm{GO}-\mathrm{NH}_{2}\right)$ are new materials that possess the properties of both GO and the amine groups. The amine groups become protonated (and therefore positively charged) in acidic solutions.

Poly(acrylic acid) (PAA) is a hydrophilic polymer that has abundant carboxyl groups, making it soluble in water and giving it a high negative charge density. ${ }^{18}$ PAA is therefore strongly electrostatically attracted to positively charged molecules. Sodium 4-amino-1-naphthalenesulfonate (ANS) is a fluorescent dye that can be used to modify PAA, giving ANS-PAA. The modification, which improves the negative charge density of the ANS, can be achieved using the 1-ethyl-3-(3-dimethylaminopropyl)carbodiimide/ $N$-hydroxysuccinimide coupling method. ANS-PAA has a high negative charge density, and it will have a strong binding affinity for protonated $\mathrm{GO}-\mathrm{NH}_{2}$ or protamines.

In the study described here we synthesized a new ANSPAA/GO- $\mathrm{NH}_{2}$ complex probe for determining protamines. The ANS-PAA is used as an indicator, and protamines are sensitively detected because of competition between the GO$\mathrm{NH}_{2}$ and protamine to bind with the indicator (as shown in Scheme 1). The fluorescence of ANS-PAA added to a solution containing the $\mathrm{GO}-\mathrm{NH}_{2}$ is quenched because the negative ANS-PAA adsorbs to the positively charged GO- $\mathrm{NH}_{2}$ surfaces through electrostatic attraction. Förster resonance energy transfer and electron transfer occur because of the proximity of the ANS-PAA and GO- $\mathrm{NH}_{2}$. However, cationic protamines will form stable inter-polyelectrolyte complexes with the anionic ANS-PAA through strong electrostatic interactions, causing the ANS-PAA to desorb from the GO- $\mathrm{NH}_{2}$ surfaces and the fluorescence of the ANS-PAA to be recovered. We found that the displacement of ANS-PAA by protamines gave a high fluorescence recovery efficiency. Protamines are detected using the GO- $\mathrm{NH}_{2}$ complex through the fluorescence turn-on process.

\section{Experimental}

\section{Materials and chemicals}

Graphite and $N$-hydroxysuccinimide were purchased from Sinopharm Chemical Reagent Co. (Shanghai, China). ANS and PAA (MW 450 000) were obtained from Aladdin (Shanghai, China). Anhydrous ethylenediamine, $\mathrm{KMnO}_{4}$, and $\mathrm{NaNO}_{3}$ were purchased from Shanghai Lingfeng Chemical Reagent Co. (Shanghai, China). 1-Ethyl-3-(3-dimethylaminopropyl)carbodiimide hydrochloride was purchased from Shanghai Medpep Co. (Shanghai, China). All of the reagents were of analytical reagent grade and were used without further purification. All solutions were prepared under ambient conditions using deionized water.

\section{Apparatus}

Scanning electron microscopy (SEM) images were obtained using a Hitachi-S4800 field emission scanning electron microscope (Hitachi High-Technologies, Tokyo, Japan). Fourier transform infrared (FTIR) spectra from 400 to $4000 \mathrm{~cm}^{-1}$ were acquired using an FTIR S-8400 instrument (Shimadzu, Kyoto, Japan) using KBr disks. Powder X-ray diffraction patterns were recorded using an XRD-6000 instrument (Shimadzu) using a Cu $\mathrm{K} \alpha$ target and a scanning rate of $8^{\circ} 2 \theta \mathrm{min}^{-1}$, from $10^{\circ}$ to $80^{\circ}$. Fluorescence spectra of all of the samples were acquired using an F-4500 instrument (Hitachi High-Technologies), using a $1.0 \mathrm{~cm} \times 1.0 \mathrm{~cm}$ quartz cell. All of the experiments were carried out at room temperature.

\section{Preparation of GO- $\mathrm{NH}_{2}$ and ANS-PAA}

The method used to synthesize GO has been described in our previous publications. The GO was prepared from purified natural graphite using a modified Hummers method. ${ }^{18,19}$ Briefly, concentrated $\mathrm{H}_{2} \mathrm{SO}_{4}(23 \mathrm{~mL})$ was added to a $250 \mathrm{~mL}$ flask containing graphite $(1.0 \mathrm{~g})$, and the mixture was kept at $0{ }^{\circ} \mathrm{C}$ in an ice bath. $\mathrm{NaNO}_{3}(0.5 \mathrm{~g})$ was added to the mixture, then $\mathrm{KMnO}_{4}(3.0 \mathrm{~g})$ was gradually added, with stirring, and the temperature of the mixture was kept below $10{ }^{\circ} \mathrm{C}$. The mixture was then stirred with a mechanical stirrer for $2 \mathrm{~h}$. The temperature was increased to $35{ }^{\circ} \mathrm{C}$, and that temperature was maintained for $12 \mathrm{~h}$. Deionized water $(140 \mathrm{~mL})$ was then added to the mixture, and the mixture was continuously stirred for $30 \mathrm{~min}$ while the temperature was increased to $90{ }^{\circ} \mathrm{C}$. A $30 \%$ $\mathrm{H}_{2} \mathrm{O}_{2}$ solution $(50 \mathrm{~mL})$ was then added and the mixture was cooled to room temperature. The mixture was then filtered and the product washed three times with $5 \% \mathrm{HCl}_{(\mathrm{aq})}$ then with deionized water until the final product reached neutral $\mathrm{pH}$. The resulting filter cake was dried in a vacuum oven. To aminate the GO complex to give $\mathrm{GO}-\mathrm{NH}_{2}$, GO $(20 \mathrm{mg})$ was added to phosphate-buffered saline $(20 \mathrm{~mL})$ and the mixture was ultrasonicated for $1 \mathrm{~h}$ to give a homogeneous GO dispersion. A $500 \quad \mathrm{mM}$ 1-ethyl-3-(3-dimethylaminopropyl)-carbodiimide hydrochloride and $N$-hydroxysuccinimide solution $(1.0 \mathrm{~mL})$ was then added to the dispersion, and the mixture was incubated for $30 \mathrm{~min}$. Ethylenediamine $(0.2 \mathrm{~mL})$ was then added, ${ }^{\mathbf{2 0 , 2 1}}$ and the mixture was incubated for another $2 \mathrm{~h}$. The mixture was then kept overnight at $4{ }^{\circ} \mathrm{C}$, then centrifuged at $8000 \mathrm{rpm}$ for $10 \mathrm{~min}$. The solid phase was then washed with deionized water. The final product, GO- $\mathrm{NH}_{2}$ nanocomposites, was obtained and dried under vacuum for $48 \mathrm{~h}$.

\section{Synthesis of ANS-PAA}

In a $20 \mathrm{~mL}$ brown bottle, purified PAA (15 mg) was dissolved in phosphate-buffered saline $(5 \mathrm{~mL})$ at $\mathrm{pH}$ 7.4. The PAA solution was then placed in an ice bath, and 1-ethyl-3-(3dimethylaminopropyl)-carbodiimide hydrochloride $(20 \mathrm{mg})$ and sulfo- $N$-hydroxysuccinimide $(10 \mathrm{mg})$ were added while the mixture was stirred using a magnetic stirrer. The mixture was stirred for $1.0 \mathrm{~h}$, then ANS (20 mg) was added, and the reaction mixture was kept in the ice bath for another $2 \mathrm{~h}$ and then at 
a

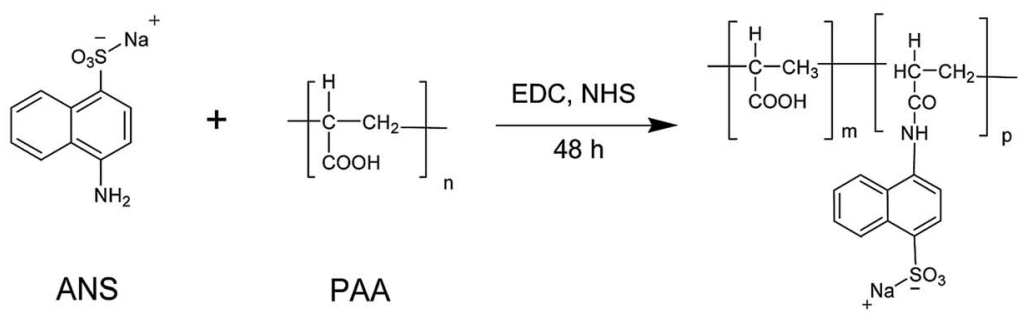

ANS-PAA

b

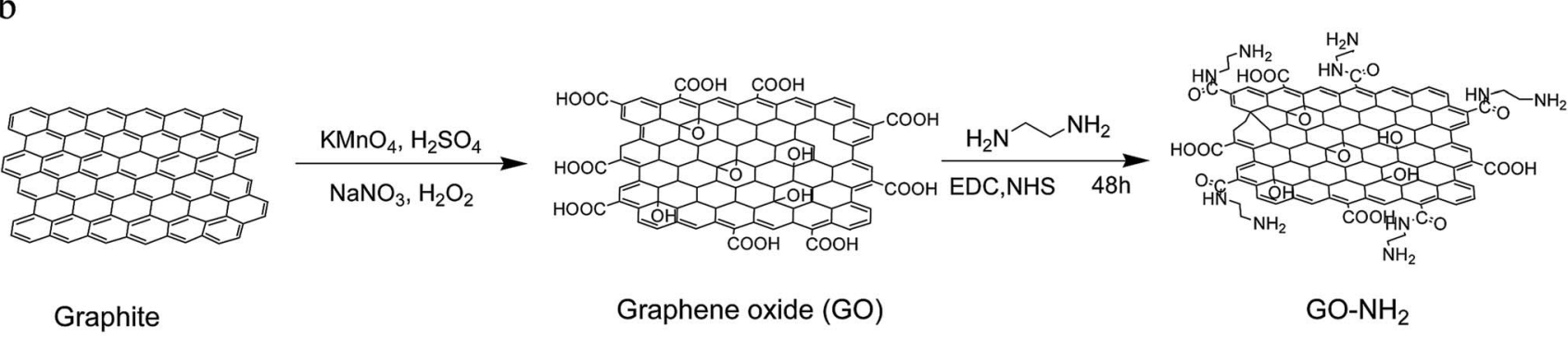

c
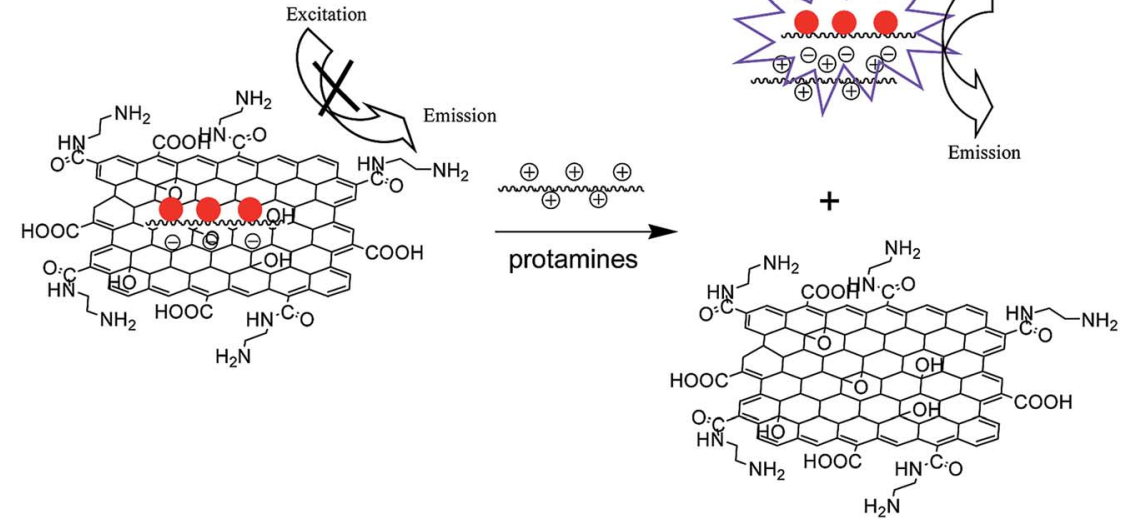

Scheme 1 Schematic illustration of (a) the preparation of polyacrylic acid (PAA) modified with sodium 4-amino-1-naphthalenesulfonate (ANS), (b) the preparation of aminated graphene oxide $\left(\mathrm{GO}-\mathrm{NH}_{2}\right)$, and (c) the rationale for the detection of protamines using the ANS-PAA/GO-NH 2 system.

room temperature for $22 \mathrm{~h}$. Once the reaction was complete, the mixture was dialyzed (with a molecular weight cutoff of $14000 \mathrm{~g}$ $\mathrm{mol}^{-1}$ ) against deionized water for three days until the conductivity of the water outside the tube remained constant. The ANS-PAA was then dried under vacuum and dissolved in water to give an ANS-PAA concentration of $1.0 \mathrm{~g} \mathrm{~L}^{-1}$.

\section{Fluorescence titration experiments}

Fluorescence measurements were made using a Hitachi F-4500 fluorescence spectrophotometer. A stock solution of ANS-PAA $\left(1.0 \mathrm{~g} \mathrm{~L}^{-1}\right)$ and a stock solution of GO-NH $\mathrm{N}_{2}\left(1.0 \mathrm{~g} \mathrm{~L}^{-1}\right)$ and protamines $\left(1.0 \mathrm{~g} \mathrm{~L}^{-1}\right)$ in water were prepared, then the ANSPAA stock solution was diluted with HEPES buffer solution to give a final concentration of $1.0 \mathrm{mg} \mathrm{L}^{-1}$. GO- $\mathrm{NH}_{2}$ was gradually added to the diluted ANS-PAA solution until the ANS-PAA fluorescence was quenched, then the required amount of protamines was added. The sample was gently stirred for $5 \mathrm{~min}$ before the fluorescence was recorded. Each experiment was performed at the optimal $\mathrm{pH}$. The fluorescence intensity of the mixture in each tube (different tubes contained different amounts of protamine) was measured using an excitation wavelength of $327 \mathrm{~nm}$, and the excitation and emission slits were both set to $5.0 \mathrm{~nm}$.

\section{Results and discussion}

\section{Characterization of the GO, GO- $\mathrm{NH}_{2}$, and ANS-PAA}

SEM images of the GO and GO- $\mathrm{NH}_{2}$ surfaces are shown in Fig. 1. It can clearly be seen that the GO sheets have typical ripples and paper-like structures. The GO- $\mathrm{NH}_{2}$ sheets, in contrast, have much rougher surfaces. 

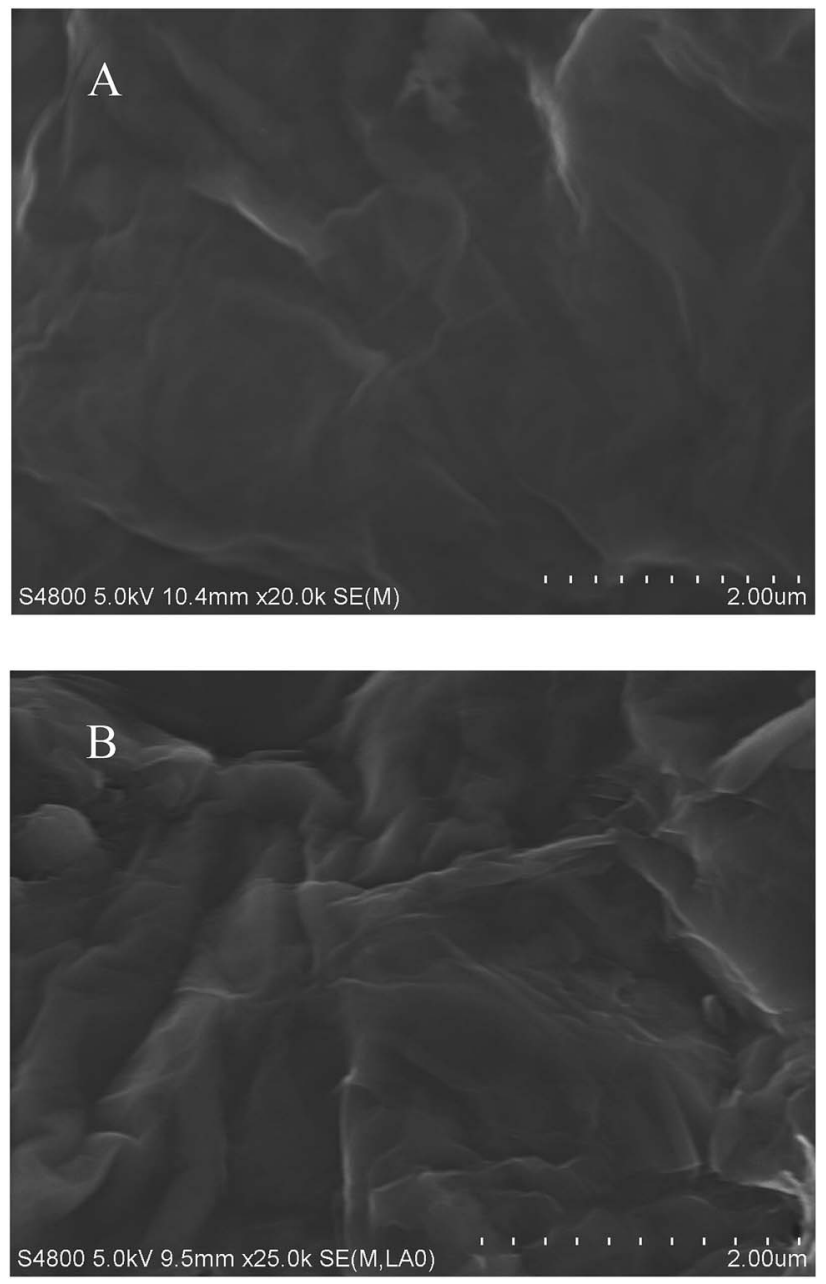

Fig. 1 SEM images of (A) graphene oxide and (B) aminated graphene oxide.

The natural graphite, $\mathrm{GO}$, and $\mathrm{GO}-\mathrm{NH}_{2}$ X-ray diffraction patterns, shown in the ESI (Fig. S1†), supported our conclusion that the GO- $\mathrm{NH}_{2}$ complex have been prepared successfully.

The structures of the natural graphite, $\mathrm{GO}, \mathrm{GO}-\mathrm{NH}_{2}$, ANS, PAA, and ANS-PAA samples are characterized using FTIR spectroscopy. As can be seen from Fig. 2, no significant bands were found in the FTIR spectrum of natural graphite. A large number of oxygen-containing functional groups are introduced when graphite is chemically treated to give GO. The strong absorption peak at $3419 \mathrm{~cm}^{-1}$ is assigned to $\mathrm{O}-\mathrm{H}$ stretching vibrations, and the peak at $1719 \mathrm{~cm}^{-1}$ is assigned to carbonyl and carboxylic group $\mathrm{C}=\mathrm{O}$ stretching vibrations. The peak at $1622 \mathrm{~cm}^{-1}$ is attributed to aromatic $\mathrm{C}=\mathrm{C}$ stretching vibrations, and the signals at 1228 and $1043 \mathrm{~cm}^{-1}$ are attributed to epoxy and alkoxy $\mathrm{C}-\mathrm{O}$ vibrations. The differences between the natural graphite and GO spectra indicated that GO have been prepared successfully. ${ }^{22,23}$ As is shown in Fig. 2A spectrum c, the FTIR spectrum of GO-NH${ }_{2}$ confirmed that the GO carboxyl groups and ethylenediamine amino groups are successfully conjugated. The peaks at 1649,1556 , and 1270 $\mathrm{cm}^{-1}$ are assigned to amide (-NHCO) group stretching
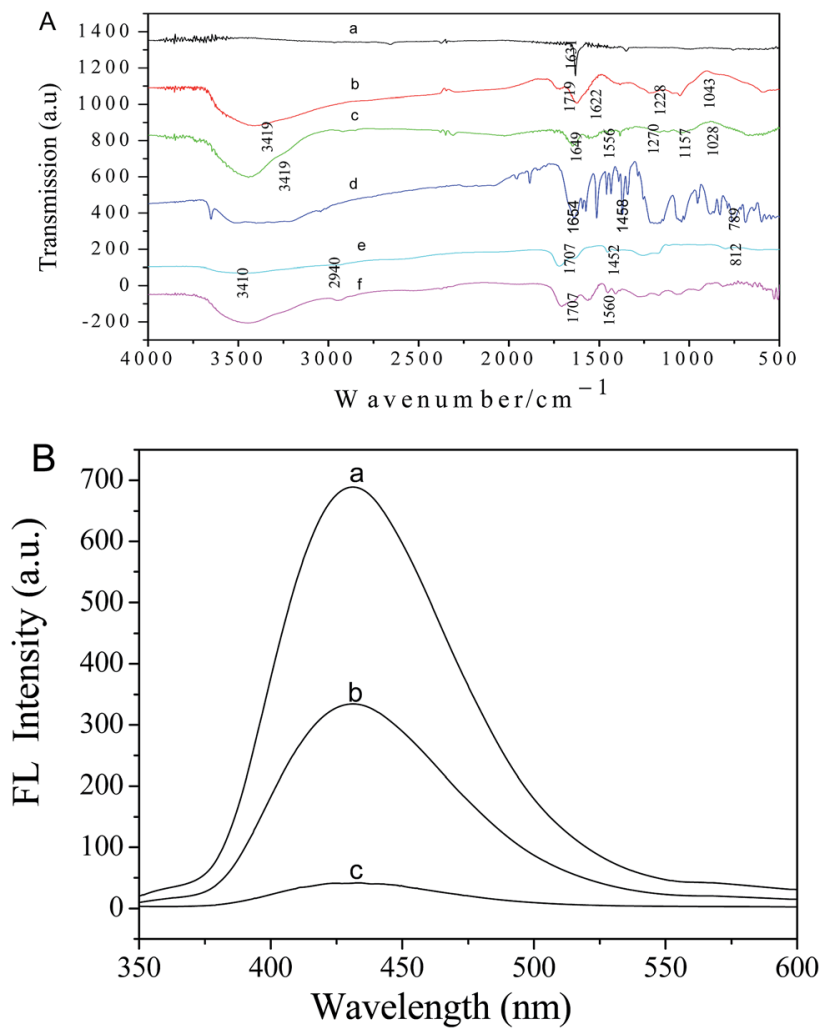

Fig. 2 Fourier transform infra-red spectra of the (A) (a) natural graphite, (b) graphene oxide, (c) aminated graphene oxide ( $\left.\mathrm{GO}-\mathrm{NH}_{2}\right)$, (d) sodium 4-amino-1-naphthalenesulfonate (ANS), (e) polyacrylic acid (PAA), and (f) the ANS-PAA complex. (B) Fluorescence emission spectra of the ANS-PAA complex in HEPES at pH 5.2 in (a) the absence of GO$\mathrm{NH}_{2}$, (b) the presence of $50 \mathrm{mg} \mathrm{L}{ }^{-1} \mathrm{GO}-\mathrm{NH}_{2}$, and (c) the presence of $75 \mathrm{mg} \mathrm{L}^{-1} \mathrm{GO}-\mathrm{NH}_{2}$.

vibrations. The carboxylic group bands found at $1719 \mathrm{~cm}^{-1}$ in the pristine $\mathrm{GO}$ spectrum are not present in the $\mathrm{GO}-\mathrm{NH}_{2}$ spectrum, supporting our conclusion that amide linkages have formed. Other peaks at $3419 \mathrm{~cm}^{-1}$ (O-H stretching vibrations), $1157 \mathrm{~cm}^{-1}$ (epoxy C-O), and $1028 \mathrm{~cm}^{-1}$ (alkoxy C-O) are also found in the $\mathrm{GO}-\mathrm{NH}_{2}$ spectrum, indicating that the expected chemical reaction have occurred and that the expected product $\mathrm{GO}-\mathrm{NH}_{2}$ have been successfully prepared. ${ }^{20,21}$ The FTIR spectrum of ANS is shown in Fig. 2A spectrum d. The peaks at 1458 and $789 \mathrm{~cm}^{-1}$ are assigned to $\mathrm{C}-\mathrm{H}$ bending vibrations, and the peak at $1654 \mathrm{~cm}^{-1}$ is attributed to $\mathrm{N}-\mathrm{H}$ bending vibrations in the ANS amino groups. The peaks at 3410 and $1707 \mathrm{~cm}^{-1}$ in the FTIR spectrum of PAA (Fig. 2A spectrum e) are attributed to $\mathrm{O}-\mathrm{H}$ and $-\mathrm{C}=\mathrm{O}$ stretching vibrations, respectively. The peak at $2940 \mathrm{~cm}^{-1}$ is attributed to symmetrical stretching of $-\mathrm{CH}_{2}-$ groups in the PAA chains, and the peaks at 1452 and $812 \mathrm{~cm}^{-1}$ are attributed to out-ofplane bending vibrations of the $\mathrm{C}-\mathrm{H}$ bonds in the PAA. The FTIR spectra of ANS and PAA are used as reference spectra. We found a peak at $1560 \mathrm{~cm}^{-1}$ in the FTIR spectrum of ANS-PAA that is not found in the ANS or PAA spectra, and this new peak indicated that the $-\mathrm{COOH}$ groups in PAA have reacted with the $-\mathrm{NH}_{2}$ groups in ANS to form amide bonds. 
Fluorescence recovery in the ANS-PAA/GO- $\mathrm{NH}_{2}$ system caused by interactions between protamine and ANS-PAA

The ANS-PAA fluorescence spectra in the absence and presence of GO-NH$H_{2}$ are shown in Fig. 2B. ANS-PAA fluoresced strongly in the absence of GO- $\mathrm{NH}_{2}$ (Fig. 2B curve a), and the fluorescence was quenched to a remarkable degree in the presence of GO$\mathrm{NH}_{2}$ (Fig. 2B curves b and c). However, the wavelength at which the maximum emission occurred and the spectral shape do not change markedly. The high quenching efficiency of GO- $\mathrm{NH}_{2}$ is caused by the ANS-PAA non-covalently binding to the GO-NH surfaces and Förster resonance energy transfer and electron transfer from the ANS-PAA to the $\mathrm{GO}-\mathrm{NH}_{2}$ occurring. One reason for this would have been that the ANS-PAA, which has a high negative charge density, will have a strong binding affinity for the positively charged GO- $\mathrm{NH}_{2}$. The high quenching efficiency meant that a good signal-to-noise ratio would be achieved when a target analyte is detected using the system and, therefore, that the system would be sensitive and have a good dynamic range for the target analyte. ${ }^{24-26}$

The ANS-PAA/GO- $\mathrm{NH}_{2}$ fluorescence sensor is tested using protamines at different concentrations in HEPES (at pH 5.2) at
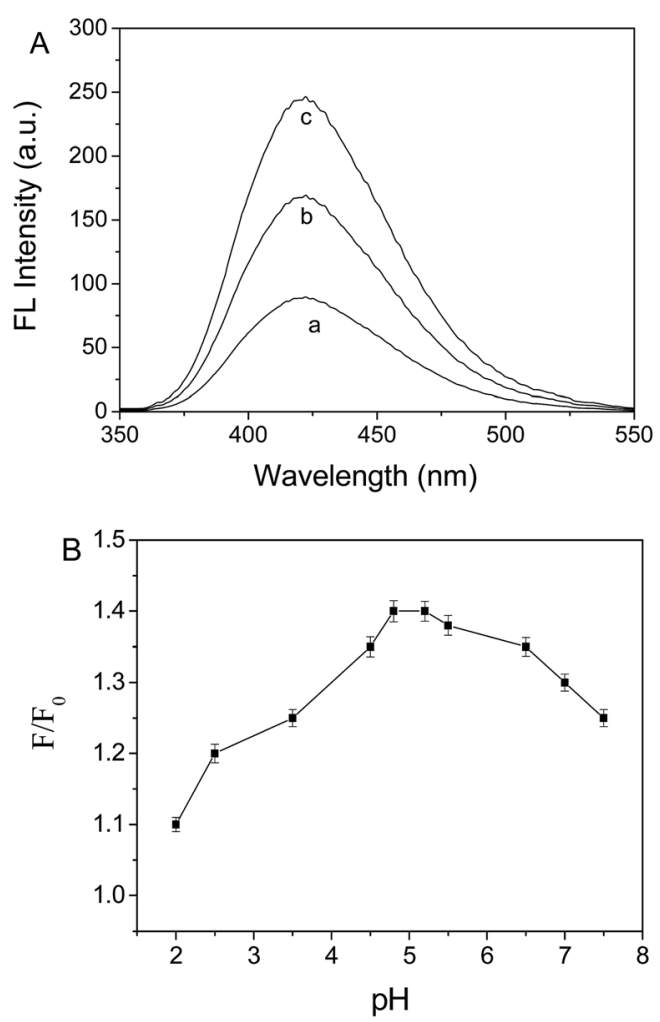

Fig. 3 (A) Fluorescence emission spectra of the polyacrylic acid modified with sodium 4-amino-1-naphthalenesulfonate (ANS-PAA) and aminated graphene oxide $\left(\mathrm{GO}-\mathrm{NH}_{2}\right)$ system in $\mathrm{HEPES}$ at $\mathrm{pH} 5.2$ in (a) the absence of protamines, (b) the presence of $2.5 \mu \mathrm{g} \mathrm{mL}^{-1}$ protamines, and (c) the presence of $4.5 \mu \mathrm{g} \mathrm{mL}^{-1}$ protamines. The ANS-PAA concentration was $1.0 \mathrm{mg} \mathrm{L}^{-1}$ and the $\mathrm{GO}-\mathrm{NH}_{2}$ concentration was $65 \mathrm{mg} \mathrm{L}^{-1}$. (B) Relative fluorescence intensities $\left(F / F_{0}\right)$ of the ANS-PAA/ $\mathrm{GO}-\mathrm{NH}_{2}$ system in the presence $(F)$ and absence $\left(F_{0}\right)$ of $2.0 \mu \mathrm{g} \mathrm{mL}^{-1}$ protamines as a function of the $\mathrm{pH}$. The ANS-PAA concentration was $1.0 \mathrm{mg} \mathrm{L}^{-1}$ and the $\mathrm{GO}-\mathrm{NH}_{2}$ concentration was $65 \mathrm{mg} \mathrm{L}^{-1}$. room temperature. As is shown in Fig. 3A, the ANS-PAA/GO-NH system fluoresced weakly, but adding protamines increased the fluorescence intensity, and the increase is related to the increase in the protamine concentration. This indicated that the protamines became bound to ANS-PAA in competition with the binding of ANS-PAA to the GO- $\mathrm{NH}_{2}$, causing ANS-PAA to become desorbed from the GO- $\mathrm{NH}_{2}$ surfaces. Protamines have more abundant negative charges than does $\mathrm{GO}-\mathrm{NH}_{2}$, so protamines will interact more strongly with ANS-PAA than will GO-NH $\mathrm{H}_{2}$. This allows protamines to remove ANS-PAA from the GO-NH surfaces, ANS-PAA/protamine complexes to form, and the ANSPAA fluorescence to be recovered. We investigated the effect of the presence of protamines on the fluorescence of ANS-PAA (Fig. S2 in the ESI $\dagger$ ), and we found that the fluorescence of ANS-PAA is not influenced by the presence of protamine. Therefore, the increase in the fluorescence of the system is attributed only to the ANS-PAA being removed from the GO- $\mathrm{NH}_{2}$ surfaces.

\section{Optimization of the conditions for detecting protamines}

The $\mathrm{pH}$ is one of the most important variables that affected the sensor system. ${ }^{27}$ The relative fluorescence intensity $F / F_{0}$ (where
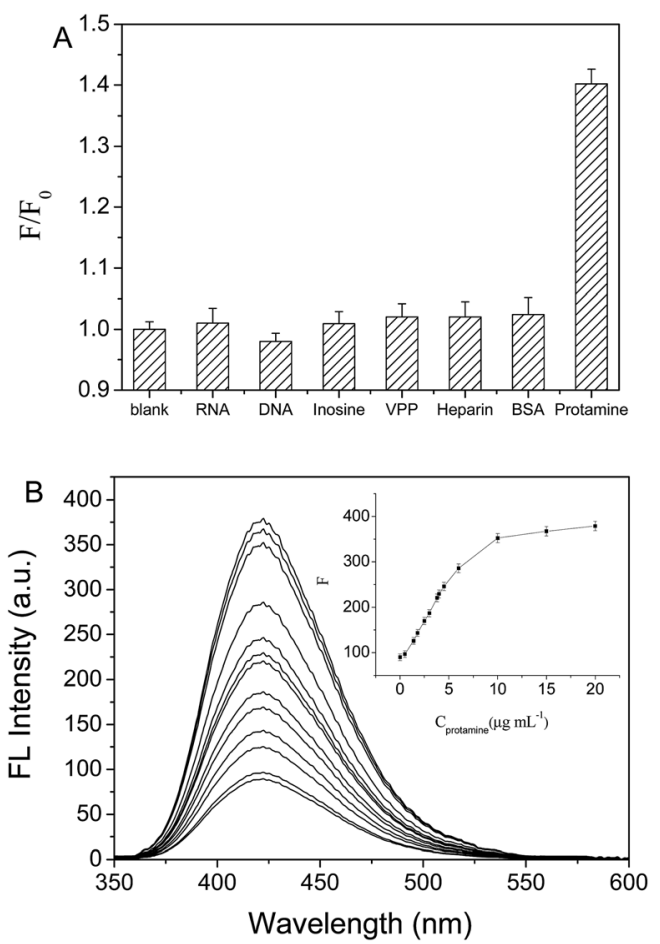

Fig. 4 (A) Fluorescence responses of the polyacrylic acid modified with sodium 4-amino-1-naphthalenesulfonate (ANS-PAA) and aminated graphene oxide $\left(\mathrm{GO}-\mathrm{NH}_{2}\right)$ system to protamines and other important biomolecules. The ANS-PAA concentration was $1.0 \mathrm{mg} \mathrm{L}^{-1}$, the $\mathrm{GO}-\mathrm{NH}_{2}$ concentration was $65 \mathrm{mg} \mathrm{L}^{-1}$, the protamine concentration was $2 \mu \mathrm{g}$ $\mathrm{mL}^{-1}$, and the concentration of each other biomolecule was $20 \mu \mathrm{g} \mathrm{mL}^{-1}$. Each solution was prepared in HEPES at pH 5.2. (B) Fluorescence emission spectra of the ANS-PAA/GO-NH $\mathrm{N}_{2}$ system in HEPES at $\mathrm{pH} 5.2$ with different protamine concentrations (from $0 \mu \mathrm{g} \mathrm{mL}^{-1}$ at the bottom to $20 \mu \mathrm{g} \mathrm{mL}^{-1}$ at the top). The inset shows the fluorescence recovery $F$ plotted against the protamine concentration. The ANS-PAA concentration was $1.0 \mathrm{mg} \mathrm{L}^{-1}$ and the $\mathrm{GO}-\mathrm{NH}_{2}$ concentration was $65 \mathrm{mg} \mathrm{L}^{-1}$. 
Table 1 Concentrations and recoveries of protamines in real samples determined using the standard addition method

\begin{tabular}{lllll}
\hline Sample & $\begin{array}{l}\text { Added } \\
\left(\mu \mathrm{g} \mathrm{mL} \mathrm{m}^{-1}\right)\end{array}$ & $\begin{array}{l}\text { Found } \\
\left(\mu \mathrm{g} \mathrm{mL} \mathrm{mL}^{-1}\right)\end{array}$ & $\begin{array}{l}\text { Recovery } \\
(\%)\end{array}$ & $\begin{array}{l}\text { RSD } \\
(\%)\end{array}$ \\
\hline Bovine serum & 0.0 & Not detected & - & - \\
samples (5\%) & 2.0 & 2.072 & 103.6 & 1.56 \\
Human serum & 0.0 & Not detected & - & - \\
samples (5\%) & 4.0 & 4.168 & 104.2 & 1.85
\end{tabular}

$F_{0}$ and $F$ are the fluorescence intensities of the ANS-PAA/GO$\mathrm{NH}_{2}$ system in the absence and presence of protamine, respectively) is determined at different $\mathrm{pH}$ values by performing fluorescence titration experiments using different initial $\mathrm{pH}$ values (between $\mathrm{pH} 2$ and 7.5) with the sensor prepared in HEPES. It can clearly be seen from Fig. 3B that the fluorescence recovery efficiency decreased gradually as the $\mathrm{pH}$ increased from $\mathrm{pH} 5.2$ to 7.5. This is probably because the protamine surfaces would have become less charged at higher $\mathrm{pH}$ values because the $-\mathrm{NH}_{3}{ }^{+}$groups would have been deprotonated. This means that fewer and weaker electrostatic interactions would occur between the protamines and the ANS-PAA at higher $\mathrm{pH}$ values. Subsequent experiments were therefore performed at pH 5.2.

\section{Interference study}

An excellent chemosensor needs to be highly selective. ${ }^{28,29}$ The selectivity of the sensor we developed for protamines was determined by using the sensor in the presence of various substances that could cause interference. We measured the fluorescence intensity of the probe in the presence of RNA, DNA, inosine, vitamin PP, heparin, or bovine serum albumin at $20 \mu \mathrm{g}$ $\mathrm{mL}^{-1}$ using the same conditions. The effect of each potentially interfering substance on the fluorescence intensity of the probe is shown in Fig. 4A. Protamines very efficiently quenched the fluorescence, and the presence of the other substances hardly changed the efficiency at which the fluorescence was quenched. We therefore concluded that the probe is outstandingly specific and selective for protamines.

\section{Analytical parameters and analyses of samples}

A plot of $F$, measured using the optimum conditions, against the protamine concentration ( $C$, in micrograms per liter) had a linear range of $0-6 \mu \mathrm{g} \mathrm{mL}{ }^{-1}$. The equation of the line was $F=$ $83.1+34.97 C$, and the correlation coefficient $\left(R^{2}\right)$ is 0.994 , as is shown in Fig. S3 in the ESI. $\uparrow$ The limit of detection $\left(C_{\text {lim }}\right)$ is determined using the equation $C_{\lim }=3 \delta / k$, where $\delta$ is the standard deviation of the concentrations found in the blanks ( $n$ $=10)$ and $k$ is the slope of the calibration line. We investigated the practicality of using the system by using a standard addition method to determine the protamine concentrations in two samples. As is shown in Table 1, the concentrations found in the two samples were $103.6 \%$ and $104.2 \%$, respectively, of the expected concentrations. These results indicated that the method can be used to determine protamine concentrations in samples accurately and reliably.

\section{Conclusions}

We developed a new type of fluorescent probe, an ANS-PAA/GO$\mathrm{NH}_{2}$ complex, for selectively and sensitively detecting protamines in aqueous solutions. The ANS-PAA fluorescence was effectively quenched by GO-NH${ }_{2}$. The high quenching efficiency was caused by the ANS-PAA non-covalently binding to the GO$\mathrm{NH}_{2}$ surfaces through electrostatic interactions, forming ANSPAA/GO-NH $\mathrm{N}_{2}$ complexes. The fluorescence of the system was recovered when protamines were added, and this was caused by the positively charged protamines removing ANS-PAA from the GO-NH $\mathrm{N}_{2}$ surfaces to form ANS-PAA/protamine complexes. Under optimal conditions, the change in the fluorescence intensity was proportional to the protamine concentration. The linear range of the probe was 0 to $6.0 \mu \mathrm{g} \mathrm{mL} \mathrm{m}^{-1}$, and the detection limit was $0.4 \mu \mathrm{g} \mathrm{mL}^{-1}$. The novel fluorescent probe has a number of attractive analytical features, being environmentally friendly, very sensitive, very selective, and simple to use and giving very reproducible results. More importantly, the proposed method will provide a basis for the development of other GO-quenched fluorescent sensors.

\section{Acknowledgements}

This work was supported by the National Natural Science Foundation of China (21205002) and the Innovation Funds of Anhui Normal University (No. 2014cxjj09).

\section{References}

1 D. Lochmann, S. Stadlhofer, J. Weyermann and A. Zimmer, Int. J. Pharm., 2004, 283, 11.

2 K. Suzuki and T. Ando, J. Biochem., 1972, 72, 1419.

3 J. A. Carr and N. Silverman, J. Cardiovasc. Surg., 1999, 40, 659.

4 B. K. Jena and C. R. Raj, Biosens. Bioelectron., 2008, 23, 1285.

5 G. A. Crespo, M. G. Afshar and E. Bakker, Angew. Chem., Int. Ed., 2012, 51, 12575.

6 A. Hvass and B. Skelbaek-Pedersen, J. Pharm. Biomed. Anal., 2005, 37, 551.

7 R. Cao and B. Li, Chem. Commun., 2011, 47, 2865.

8 Z. Yao, W. Ma, Y. Yang, X. Chen, L. Zhang, C. Lin and H. Wu, Org. Biomol. Chem., 2013, 11, 6466.

9 A. A. Ensafi, N. Kazemifard and B. Rezaei, Biosens. Bioelectron., 2015, 71, 243.

10 S. Pang, S. Y. Liu and X. G. Su, RSC Adv., 2014, 4, 25857.

11 X. Chen, Y. Xiang, N. Li, P. Song and A. Tong, Analyst, 2010, 135, 1098.

12 Q. Long, J. N. Zhao, B. D. Yin, H. T. Li, Y. Y. Zhang and S. Z. Yao, Anal. Biochem., 2015, 477, 28.

13 F. F. Xue, L. Z. Liu, Y. Y. Mi, H. Y. Han and J. G. Liang, RSC Adv., 2016, 6, 10215.

14 Y. Cao, S. Shi, L. Wang, J. Yao and T. Yao, Biosens. Bioelectron., 2014, 55, 174. 
15 Z. P. Liu, C. S. Tian, L. H. Lu and X. G. Su, RSC Adv., 2016, 6, 10205.

16 Y. Zhou, X. J. Xing, D. W. Pang and H. W. Tang, RSC Adv., 2015, 5, 12994.

17 Y. He and B. N. Jiao, RSC Adv., 2015, 5, 101327.

18 J. Liu, G. Liu and W. Liu, Chem. Eng. J., 2014, 257, 299.

19 L. Fan, C. Luo, M. Sun, H. Qiu and H. Qiu, Synthesis of graphene oxide decorated with magnetic cyclodextrin for fast chromium removal, J. Mater. Chem., 2012, 22, 24577.

20 S. Adewuyi, D. A. Ondigo, R. Zugle, Z. Tshentu, T. Nyokong and N. Torto, Anal. Methods, 2012, 4, 1729.

21 X. Liu, Z. Wang, J. Zhu, Y. Zheng, S. Cui, M. Lan and H. Li, Colloids Surf., A, 2014, 448, 119.

22 Y. L. F. Musico, C. M. Santos, M. L. P. Dalida and D. F. Rodrigues, J. Mater. Chem. A, 2013, 1, 3789.
23 W. Zhang, X. Shi, Y. Zhang, W. Gu, B. Li and Y. Xian, J. Mater. Chem. A, 2013, 1, 1745.

24 J. F. Liang, R. Wei, S. He, Y. K. Liu, L. Guo and L. D. Li, Analyst, 2013, 138, 1726.

25 J. Li, Y. Li, S. A. Shahzad, J. Chen, Y. Chen, Y. Wang, M. Yang and C. Yu, Chem. Commun., 2015, 51, 6354.

26 S. Basiruddin and S. K. Swain, Mater. Sci. Eng., C, 2016, 58, 103.

27 K. Srinivasan, K. Subramanian, K. Murugan and K. Dinakaran, Analyst, 2016, 141, 6344.

28 S. H. Jung, T. K. Hyun, J. Kim and J. H. Jung, RSC Adv., 2015, 5, 26662.

29 A. Pandith, A. Kumar and H. Kim, RSC Adv., 2015, 5, 81808. 